\title{
Higher Serum Vitamin D Concentrations Are Longitudinally Associated with Better Global Quality of Life and Less Fatigue in Colorectal Cancer Survivors up to 2 Years after Treatment
}

Citation for published version (APA):

Koole, J. L., Bours, M. J. L., van Roekel, E. H., Breedveld-Peters, J. J. L., van Duijnhoven, F. J. B., van den Ouweland, J., Breukink, S. O., Janssen-Heijnen, M. L. G., Keulen, E. T. P., \& Weijenberg, M. P. (2020). Higher Serum Vitamin D Concentrations Are Longitudinally Associated with Better Global Quality of Life and Less Fatigue in Colorectal Cancer Survivors up to 2 Years after Treatment. Cancer Epidemiology Biomarkers \& Prevention, 29(6), 1135-1144. https://doi.org/10.1158/1055-9965.epi-19-1522

Document status and date:

Published: 01/06/2020

DOI:

10.1158/1055-9965.epi-19-1522

Document Version:

Publisher's PDF, also known as Version of record

Document license:

Taverne

Please check the document version of this publication:

- A submitted manuscript is the version of the article upon submission and before peer-review. There can be important differences between the submitted version and the official published version of record. People interested in the research are advised to contact the author for the final version of the publication, or visit the DOI to the publisher's website.

- The final author version and the galley proof are versions of the publication after peer review.

- The final published version features the final layout of the paper including the volume, issue and page numbers.

Link to publication

\footnotetext{
General rights rights.

- You may freely distribute the URL identifying the publication in the public portal. please follow below link for the End User Agreement:

www.umlib.nl/taverne-license

Take down policy

If you believe that this document breaches copyright please contact us at:

repository@maastrichtuniversity.nl

providing details and we will investigate your claim.
}

Copyright and moral rights for the publications made accessible in the public portal are retained by the authors and/or other copyright owners and it is a condition of accessing publications that users recognise and abide by the legal requirements associated with these

- Users may download and print one copy of any publication from the public portal for the purpose of private study or research.

- You may not further distribute the material or use it for any profit-making activity or commercial gain

If the publication is distributed under the terms of Article 25fa of the Dutch Copyright Act, indicated by the "Taverne" license above, 


\title{
Higher Serum Vitamin D Concentrations Are Longitudinally Associated with Better Global Quality of Life and Less Fatigue in Colorectal Cancer Survivors up to 2 Years after Treatment
}

\author{
Janna L. Koole', Martijn J.L. Bours', Eline H. van Roekel', José J.L. Breedveld-Peters',
} Fränzel J.B. van Duijnhoven ${ }^{2}$, Jody van den Ouweland ${ }^{3}$, Stéphanie O. Breukink ${ }^{4}$, Maryska L.G. Janssen-Heijnen ${ }^{1,5}$, Eric T.P. Keulen ${ }^{6}$, and Matty P. Weijenberg ${ }^{1}$

\section{ABSTRACT}

Background: Vitamin D status may be an important determinant of health-related quality of life of colorectal cancer survivors. The current study investigated longitudinal associations between serum 25 -hydroxyvitamin $\mathrm{D}_{3}\left(25 \mathrm{OHD}_{3}\right)$ concentrations and quality of life in stage I-III colorectal cancer survivors up to 2 years after treatment.

Methods: Patients with colorectal cancer $(n=261)$ were included upon diagnosis. Home visits (including blood sampling) were performed at diagnosis and at 6 weeks, 6 months, 1 year, and 2 years after treatment. Serum $25 \mathrm{OHD}_{3}$ concentrations were measured using LC/MS-MS and adjusted for season. Validated questionnaires were used to assess global quality of life and cognitive functioning (EORTC-QLQ-C30), fatigue (EORTC-QLQ-C30 and Checklist Individual Strength, CIS), and depression and anxiety (Hospital Anxiety and Depression Scale). Statistical analyses were performed using linear mixed models and adjusted for sex, age, time since diagnosis, therapy, comorbidities, physical activity, and body mass index.

\section{Introduction}

Colorectal cancer survivors are susceptible to enduring physical and psychologic distress as a result of the tumor and therapy. A growing number of individuals are living with a history of colorectal cancer given the improving 5-year survival rate after colorectal cancer, currently $65 \%$ in the Netherlands $(1,2)$. Previous studies reported complaints of fatigue by more than one third of Dutch colorectal cancer survivors, especially within 5 years after diagnosis (3-5).

'Department of Epidemiology, GROW School for Oncology and Developmental Biology, Maastricht University, Maastricht, the Netherlands. ${ }^{2}$ Division of Human Nutrition and Health, Wageningen University and Research, Wageningen, the Netherlands. ${ }^{3}$ Department of Clinical Chemistry, Canisius-Wilhelmina Hospital, Nijmegen, the Netherlands. ${ }^{4}$ Department of Surgery, GROW School for Oncology and Developmental Biology, Maastricht University Medical Centre+, Maastricht, the Netherlands. ${ }^{5}$ Department of Clinical Epidemiology, VieCuri Medical Centre, Venlo, the Netherlands. ${ }^{6}$ Department of Internal Medicine and Gastroenterology, Zuyderland Medical Centre, Sittard, the Netherlands.

Note: Supplementary data for this article are available at Cancer Epidemiology, Biomarkers \& Prevention Online (http://cebp.aacrjournals.org/).

Corresponding Author: Janna L. Koole, Maastricht University, 6229HA Maastricht, the Netherlands. Phone: 314-3388-2043; Fax: 314-3388-4128; E-mail: annaleen.koole@maastrichtuniversity.nl

Cancer Epidemiol Biomarkers Prev 2020;29:1135-44

doi: 10.1158/1055-9965.EPI-19-1522

(c)2020 American Association for Cancer Research.
Results: At diagnosis, $45 \%$ of patients were vitamin D deficient $(<50 \mathrm{nmol} / \mathrm{L})$. After treatment, $25 \mathrm{OHD}_{3}$ concentrations increased on average with $3.1 \mathrm{nmol} / \mathrm{L}$ every 6 months. In confounder-adjusted models, $20 \mathrm{nmol} / \mathrm{L}$ increments in $25 \mathrm{OHD}_{3}$ were longitudinally associated with increased global quality of life $[\beta 2.9 ; 95 \%$ confidence interval $(\mathrm{CI}), 1.5-4.3]$ and reduced fatigue (EORTC-QLQ-C30 subscale: $\beta-3.5$; 95\% CI, -5.3 to -1.8 and CIS: $\beta-2.8 ; 95 \% \mathrm{CI},-4.7$ to -0.9$)$. Observed associations were present both within and between individuals over time.

Conclusions: Higher concentrations of $25 \mathrm{OHD}_{3}$ were longitudinally associated with better global quality of life and less fatigue in colorectal cancer survivors.

Impact: This study suggests that higher $25 \mathrm{OHD}_{3}$ concentrations may be beneficial for colorectal cancer survivors. Future intervention studies are needed to corroborate these findings.

In addition, colorectal cancer survivors are at increased risk of impaired cognitive functioning and mental health problems such as depression (6-8).

Vitamin $\mathrm{D}$ is a potentially important determinant of health-related quality of life (HRQoL) of colorectal cancer survivors given its involvement in many cellular processes related to cognition $(9,10)$, depression $(11,12)$, and fatigue (13). Exposure of the skin to ultraviolet B radiation contributes to about two thirds of vitamin D supply, whereas about one third originates from vitamin D intake (14). Vitamin D deficiencies have become a concern of public health $(15,16)$ and the Dutch Health Council recommends women aged 50 to $70(10 \mathrm{mcg})$ and men and women aged $>70(20 \mathrm{mcg})$ to daily supplement vitamin $\mathrm{D}$ (14). No specific guidelines for cancer survivors are available. To maintain adequate vitamin $\mathrm{D}$ concentrations, 15 to 30 minutes of daily sunlight exposure from March to November is generally sufficient for the general population (17). Colorectal cancer survivors are at risk of low vitamin $\mathrm{D}$ because of the negative impact of the cancer and chemotherapy on circulating concentrations (18-20). Moreover, the association between low vitamin D and increased colorectal cancer risk (21-24) makes colorectal cancer survivors particularly susceptible as low concentrations may be sustained after therapy. Inflammation may be an important confounder in the association between vitamin D and HRQoL. Inflammatory processes and vitamin $\mathrm{D}$ interact through 1,25-dihydroxyvitamin $\mathrm{D}$, the biologically active metabolite also known as calcitriol, which is engaged in different intracellular inflammatory reactions (25). In addition, as inflammatory markers have been associated with increased fatigue 
after cancer, a potential observed association between vitamin $\mathrm{D}$ and HRQoL may be altered by inflammation (26).

Few studies have investigated associations between vitamin $\mathrm{D}$ and HRQoL after colorectal cancer. An observational study among 453 stage II colorectal cancer survivors reported better symptom-related quality of life among participants using vitamin D supplements over 2 years of follow-up (27). Cancer survivors are known to be highly motivated to intentionally alter their lifestyle in order to make health improvements (28). Therefore, lifestyle recommendations that focus on the enhancement of vitamin D concentrations may be an opportunity to prevent or reduce problems of diminished HRQoL after colorectal cancer.

The objective of the present study was to investigate longitudinal associations of serum 25-hydroxyvitamin D3 $\left(25 \mathrm{OHD}_{3}\right)$ concentrations with HRQoL in colorectal cancer survivors from 6 weeks to 2 years after treatment, including global quality of life, fatigue, depression, anxiety, and cognitive functioning.

\section{Materials and Methods \\ Study design and population}

The EnCoRe study (Energy for Life after ColoRectal Cancer) is an ongoing prospective cohort study that was initiated in 2012 (Netherlands Trial Register no. NL6904; refs. 5, 29). The purpose of the EnCoRe study is to evaluate longitudinal associations between lifestyle factors and HRQoL, functioning, and prognosis after colorectal cancer. Patients with stage I-III colorectal cancer $\geq 18$ years of age were recruited at diagnosis. Research dietitians performed home visits at diagnosis (prior to treatment) and at 6 weeks, 6 months, 1 year, and 2 years after the end of treatment. The study was approved by the Medical Ethics Committee of the University Hospital Maastricht and Maastricht University, the Netherlands. All participants signed informed consent. Exclusion criteria were: diagnosis with stage IV colorectal cancer, no home address in the Netherlands, inability to understand the Dutch language, and the presence of comorbidities obstructing successful study participation. Data used in the current analyses were based on the first 4.5 years of follow-up until November 1, 2016. Participants with at least 1 follow-up visit with available data on both $25 \mathrm{OHD}_{3}$ and $\mathrm{HRQ}$ oL were included in the current analyses. The final analyses contained 261 participants at diagnosis, 260 at 6 weeks, 213 at 6 months, 168 at 12 months, and 77 at 24 months after treatment. Response rate for inclusion was $46 \%$ and $>90 \%$ for followup visits.

\section{Measurement of $250 \mathrm{HD}_{3}$}

At diagnosis, blood samples were drawn either during the first home visit or at the hospital, and were mostly nonfasting. At follow-up, fasting blood samples were drawn during home visits. Samples were collected in $8.5 \mathrm{~mL}$ serum tubes (BD Vacutainer SST II Advance) and pipetted into aliquots after centrifugation. Aliquots were stored at $-80^{\circ} \mathrm{C}$ within 4 hours after blood draw until analysis. Serum $25 \mathrm{OHD}_{3}$ concentrations were measured using LC/MS-MS at the CanisiusWilhelmina Hospital in Nijmegen, the Netherlands (30). Interassay coefficients of variation were $5.3 \%, 3.1 \%$, and $2.9 \%$ at $25 \mathrm{OHD}_{3}$ concentrations of $39.0,92.5$, and $127.0 \mathrm{nmol} / \mathrm{L}$, respectively. $25 \mathrm{OHD}_{3}$ concentrations are a robust indicator and the most commonly used marker of vitamin D status (31).

\section{Health-related quality of life}

HRQoL was assessed during posttreatment time points. Global quality of life, cognitive functioning, and fatigue were assessed by the Quality of Life Questionnaire of the European Organisation for
Research and Treatment of Cancer (EORTC QLQ-C30, version 3.0; refs. 32, 33). Higher scores reflect better global quality of life, better cognitive functioning, and more fatigue (range, 0-100). Fatigue was also measured by the Checklist Individual Strength (CIS), a validated 20 -item questionnaire that has been used in colorectal cancer survivors before $(34,35)$. Higher scores indicate more fatigue (range, 20-140). Depression and anxiety were assessed using the Hospital Anxiety and Depression Scale (HADS; refs. 36, 37). The HADS includes separate depression and anxiety scales, and higher scores indicate more depression and anxiety (range, $0-42$ ).

\section{Sociodemographic, lifestyle, and clinical data}

Sociodemographic information was collected based on self-report. Cancer stage, type of therapy, and other clinical information were obtained from medical records. Information on comorbidities at diagnosis was retrieved from medical records by the Charlson Comorbidity Index (38) and during follow-up from the Self-Administered Comorbidity Questionnaire, which included heart condition; stroke; high blood pressure; asthma, chronic bronchitis, or chronic obstructive pulmonary disease; diabetes; stomach ulcer; kidney disease; liver disease; anemia or other disease of the blood; thyroid gland disease; depression; osteoarthritis; back pain; and rheumatoid arthritis (39).

Information on dietary supplement use, including vitamin D supplements, was collected during home visits. Information on (brand) name, dosage, frequency, duration, and ingredients was listed on standardized forms. Vitamin D intake from supplements was calculated in micrograms per day by multiplying daily frequency and dosage. At diagnosis, participants completed a semiquantitative 253-item food frequency questionnaire to retrospectively assess dietary vitamin D intake during the preceding year (40). Participants completed a 7-day dietary record as part of each posttreatment followup visit. Vitamin D levels in food products for both methods were obtained from the 2011 Dutch Food Composition Database (41). Methods were described in more detail previously $(5,42)$.

Measurements of height and weight were performed during home visits to determine body mass index (BMI). Physical activity was selfreported using the Short QUestionnaire to ASsess Health enhancing physical activity (SQUASH). Time spent in moderate-to-vigorous physical activity (MVPA; $\geq 3$ metabolic equivalents of task) was calculated in hours/week (43). Sun exposure was self-reported at each time point by the number of days per week that participants had spent at least 15 minutes outside (in daylight), on average over the preceding month. The variable was dichotomized for the analyses in order to reflect adherence to the Dutch recommendations regarding sun exposure (spent 15 minutes outside on 7 or $<7$ days/week).

Plasma concentrations of inflammation markers IL6, IL8, IL10, and TNF $\alpha$ were measured for all time points. The selection of this set of inflammation markers was based on a review that evaluated inflammation markers that interact with vitamin $\mathrm{D}$ and that are specifically relevant in relation to colorectal cancer (25). Samples were collected in $6.0 \mathrm{~mL}$ EDTA plasma tubes (BD Vacutainer K2E) and pipetted into aliquots after centrifugation. Aliquots were stored at $-80^{\circ} \mathrm{C}$ within 4 hours after blood draw until analysis. Measurements were performed using a custom-made multiplex assay and electrochemiluminescence (Meso Scale Diagnostics) at Wageningen University and Research, the Netherlands. Assay plates were analyzed on a QuickPlex SQ 120 plate reader (Meso Scale Diagnostics).

\section{Statistical analyses}

Descriptive analyses were performed to calculate means and SD for normally distributed variables and medians and interquartile ranges 
Vitamin D and Quality of Life after Colorectal Cancer

Table 1. Sociodemographic and clinical characteristics of study participants at time of inclusion (colorectal cancer diagnosis), included in the EnCoRe study.

\begin{tabular}{|c|c|c|c|}
\hline & \multirow{3}{*}{$\begin{array}{l}\text { Total population } \\
\quad(n=261)^{\mathrm{a}}\end{array}$} & \multicolumn{2}{|c|}{ Vitamin D deficiency } \\
\hline & & \multicolumn{2}{|c|}{$(<50 \mathrm{nmol} / \mathrm{L})^{\mathrm{b}}$} \\
\hline & & Yes $(n=111)$ & No $(n=136)$ \\
\hline Age, mean (SD) & $67(9)$ & $67(9)$ & $66(9)$ \\
\hline \multicolumn{4}{|l|}{ Sex, $n(\%)$} \\
\hline Men & $179(69)$ & $78(70)$ & $91(67)$ \\
\hline Women & $82(31)$ & $33(30)$ & $45(33)$ \\
\hline \multicolumn{4}{|l|}{ Education level, $n$ (\%) } \\
\hline Low & $66(25)$ & $26(23)$ & $35(26)$ \\
\hline Medium & $105(40)$ & $48(43)$ & $53(39)$ \\
\hline High & $89(34)$ & $37(33)$ & $47(35)$ \\
\hline \multicolumn{4}{|l|}{ Cancer type, $n(\%)$} \\
\hline Colon & $159(61)$ & $72(65)$ & $79(58)$ \\
\hline Rectum & $102(39)$ & $39(35)$ & $57(42)$ \\
\hline \multicolumn{4}{|l|}{ Cancer stage $^{\mathrm{c}}, n(\%)$} \\
\hline 1 & $77(30)$ & $32(30)$ & $43(34)$ \\
\hline II & $60(23)$ & $26(24)$ & $27(21)$ \\
\hline III & $113(43)$ & $50(46)$ & $58(45)$ \\
\hline \multicolumn{4}{|l|}{ Treatment, $n(\%)$} \\
\hline Neither chemotherapy nor radiotherapy & $143(55)$ & $60(54)$ & $77(57)$ \\
\hline Chemotherapy only & $46(18)$ & $25(23)$ & $18(13)$ \\
\hline Radiotherapy only & $20(8)$ & $6(5)$ & $10(7)$ \\
\hline Both chemotherapy and radiotherapy & $52(20)$ & $20(18)$ & $31(23)$ \\
\hline \multicolumn{4}{|l|}{ Inflammatory markers, median (IQR) } \\
\hline IL6 in pg/mL & $1.1(0.7-1.7)$ & $1.2(0.8-1.8)$ & $1.0(0.6-1.6)$ \\
\hline IL8 in pg/mL & $5.5(4.4-8.0)$ & $5.7(4.4-8.0)$ & $5.5(4.5-7.9)$ \\
\hline IL10 in pg/mL & $0.3(0.2-0.4)$ & $0.3(0.2-0.4)$ & $0.3(0.2-0.4)$ \\
\hline $\mathrm{TNF} \alpha$ in $\mathrm{pg} / \mathrm{mL}$ & $2.2(1.8-2.8)$ & $2.2(1.9-2.7)$ & $2.2(1.7-2.8)$ \\
\hline Summary z-score & $-0.1(-1.4$ to 1.1$)$ & $-0.1(-1.0$ to 1.2$)$ & $-0.1(-1.6$ to 1.1$)$ \\
\hline \multicolumn{4}{|l|}{ Sun exposure ${ }^{d}, n(\%)$} \\
\hline$<7$ days & $87(33)$ & $41(37)$ & $41(30)$ \\
\hline 7 days & $173(67)$ & $70(63)$ & $94(70)$ \\
\hline \multicolumn{4}{|l|}{ Number of comorbidities, $n$ (\%) } \\
\hline None & 49 (19) & $18(16)$ & $29(21)$ \\
\hline 1 & $57(22)$ & $21(19)$ & $36(26)$ \\
\hline$\geq 2$ & $155(59)$ & $72(65)$ & $71(52)$ \\
\hline BMI in $\mathrm{kg} / \mathrm{m}^{2}$, mean (SD) & $28.4(4.5)$ & $29.2(5.0)$ & $27.6(4.1)$ \\
\hline \multicolumn{4}{|l|}{ Physical activity, median (IQR) } \\
\hline LPA (hours/week) & $11(4-23)$ & $11(4-21)$ & $12(4-30)$ \\
\hline MVPA (hours/week) & $11(5-20)$ & $11(4-19)$ & $12(6-21)$ \\
\hline \multicolumn{4}{|l|}{ Current smoking, $n(\%)$} \\
\hline Yes & 33 (13) & $15(14)$ & $16(12)$ \\
\hline No & 227 (87) & $96(86)$ & 119 (88) \\
\hline
\end{tabular}

Abbreviations: BMI, body mass index; LPA, light physical activity; MVPA, moderate-to-vigorous physical activity.

${ }^{a}$ The number of participants may slightly vary for the different variables given a small percentage of missing data.

${ }^{\mathrm{b}}$ Fourteen participants had unknown $25 \mathrm{OHD}_{3}$ status at time of inclusion.

'Eleven participants had missing stage I, II, or III colorectal cancer.

${ }^{\mathrm{d}}$ Number of days per week spent at least 15 minutes outside (in daylight), on average over the preceding 4 weeks.

(IQR) for skewed variables. $25 \mathrm{OHD}_{3}$ concentrations at each time point were adjusted for season using the week (1-52) of blood collection. Locally weighted regression analyses (LOWESS) were performed in order to account for the variation caused by seasonal differences $(44,45)$. For posttreatment time points, longitudinal associations between $25 \mathrm{OHD}_{3}$ concentrations and HRQoL were investigated using linear mixed-model analyses. Each model contained a random intercept for subject. The addition of a random slope for vitamin D was evaluated in each model according to the change in log-restricted likelihood values. A separate model was used to disentangle inter- and intraindividual associations (46). Interindividual associations were estimated by the centered person-mean value, indicating the difference between participants' mean $25 \mathrm{OHD}_{3}$ concentrations over time. Intraindividual associations were estimated by the individual deviations from the person-mean, indicating individual changes in vitamin D concentration over time. Vitamin D was modeled as a continuous variable in units of $20 \mathrm{nmol} / \mathrm{L}$ and as a dichotomous variable (vitamin D concentration $<50 \mathrm{nmol} / \mathrm{L}$; yes/no; ref. 20 ). In addition, scoring on the outcomes was compared for $25 \mathrm{OHD}_{3}$ concentrations of $<30 \mathrm{nmol} / \mathrm{L}, 30-50 \mathrm{nmol} / \mathrm{L}$, and $>50 \mathrm{nmol} / \mathrm{L}$. Vitamin D supplement use (yes/no), total vitamin D intake from diet and supplements $(\mu \mathrm{g} /$ day), and vitamin D intake only from supplements ( $\mu \mathrm{g} /$ day) were 
Table 2. Descriptive statistics of $25 \mathrm{OHD}_{3}$ concentrations, vitamin D supplement use and dietary intake, HRQL outcomes, and other important characteristics of patients with colorectal cancer from the EnCoRe study, from inclusion (colorectal cancer diagnosis) to 24 months after treatment.

\begin{tabular}{|c|c|c|c|c|c|}
\hline & & & osttreatment follo & w-up measuremen & \\
\hline & $\begin{array}{l}\text { At diagnosis } \\
n=261^{\mathrm{a}}\end{array}$ & $\begin{array}{l}6 \text { weeks } \\
\text { after treatment } \\
n=260\end{array}$ & $\begin{array}{l}6 \text { months } \\
\text { after treatment } \\
n=213\end{array}$ & $\begin{array}{l}12 \text { months } \\
\text { after treatment } \\
n=168\end{array}$ & $\begin{array}{l}\text { 24 months } \\
\text { after treatment } \\
n=77\end{array}$ \\
\hline $\begin{array}{l}25 \mathrm{OHD}_{3} \text { concentration in nmol/L, median (IQR) } \\
\text { Vitamin D deficiency, } n(\%)\end{array}$ & $53.1(40.6-67.6)$ & $48.0(35.2-66.1)$ & $53.4(41.8-69.4)$ & $57.0(42.5-70.5)$ & $62.9(46.5-82.4)$ \\
\hline Yes $(<50 \mathrm{nmol} / \mathrm{L})$ & $111(45)$ & $133(53)$ & $87(42)$ & $60(36)$ & $22(30)$ \\
\hline No $(\geq 50 \mathrm{nmol} / \mathrm{L})$ & $136(55)$ & $120(47)$ & $120(58)$ & $106(64)$ & $52(70)$ \\
\hline Vitamin D supplement use, $n(\%)$ & & & & & \\
\hline Yes & $62(24)$ & $49(19)$ & $44(21)$ & $38(23)$ & $17(22)$ \\
\hline No & $194(76)$ & $207(81)$ & $163(79)$ & $129(77)$ & $60(78)$ \\
\hline Vitamin D intake from supplements in $\mu \mathrm{g} / \mathrm{d}$, median (IQR) & $5(5-10)$ & $5(5-10)$ & $6(5-15)$ & $7(5-20)$ & $10(5-20)$ \\
\hline Dietary vitamin $D$ intake ${ }^{b}$ in $\mu \mathrm{g} / \mathrm{d}$, median (IQR) & $3.5(2.5-4.7)$ & $4.1(2.9-5.6)$ & $3.7(2.8-4.7)$ & $3.8(2.9-5.0)$ & $3.7(2.6-4.6)$ \\
\hline EORTC QLQ-C3OC & & & & & \\
\hline Global quality of life, mean (SD) & & $74.1(18.3)$ & $76.9(19.0)$ & $77.8(18.0)$ & $79.6(18.5)$ \\
\hline Range (min-max) & & $16.7-100$ & $0-100$ & $0-100$ & $33.3-100$ \\
\hline Cognitive functioning, mean (SD) & & $86.3(20.8)$ & $85.9(19.1)$ & $87.6(19.4)$ & $87.7(15.1)$ \\
\hline Range (min-max) & & $0-100$ & $16.7-100$ & $16.7-100$ & $33.3-100$ \\
\hline Fatigue, mean (SD) & & $29.1(23.0)$ & $23.6(21.6)$ & $21.6(23.0)$ & $19.3(21.5)$ \\
\hline Range (min-max) & & $0-100$ & $0-100$ & $0-100$ & $0-88.9$ \\
\hline CIS (incl. 4 subscales) ${ }^{d}$ & & & & & \\
\hline Total fatigue, mean (SD) & & $62.9(26.4)$ & $59.3(27.4)$ & $54.0(25.9)$ & $51.5(25.2)$ \\
\hline Range (min-max) & & $20-127$ & $20-132$ & $20-134$ & $20-101$ \\
\hline Subjective fatigue, mean (SD) & & $27.2(13.3)$ & $24.9(12.8)$ & $22.6(12.3)$ & $21.3(12.8)$ \\
\hline Range (min-max) & & $8-56$ & $8-56$ & $8-56$ & $8-54$ \\
\hline Reduced motivation, mean (SD) & & $12.3(6.1)$ & $12.0(6.2)$ & $10.9(6.1)$ & $10.5(5.9)$ \\
\hline Range (min-max) & & $4-28$ & $4-27$ & $4-28$ & $4-27$ \\
\hline Reduced physical activity, mean (SD) & & $10.6(5.1)$ & $9.6(5.1)$ & $8.6(5.0)$ & $8.1(4.8)$ \\
\hline Range (min-max) & & $3-21$ & $3-21$ & $3-21$ & $3-21$ \\
\hline Concentration problems, mean (SD) & & $12.9(7.3)$ & $12.8(7.3)$ & $11.9(6.7)$ & $11.6(6.5)$ \\
\hline Range (min-max) & & $5-34$ & $5-33$ & $5-31$ & $5-28$ \\
\hline HADS (incl. 2 subscales) ${ }^{\mathrm{e}}$ & & & & & \\
\hline Total depression and anxiety, mean (SD) & & $7.4(6.4)$ & $7.4(6.7)$ & $6.8(6.2)$ & $5.6(5.5)$ \\
\hline Range (min-max) & & $0-30$ & $0-32$ & $0-33$ & $0-28$ \\
\hline Depression, mean (SD) & & $3.8(3.6)$ & $3.9(3.9)$ & $3.4(3.4)$ & $2.7(3.1)$ \\
\hline Range (min-max) & & $0-15$ & $0-19$ & $0-17$ & $0-14$ \\
\hline Anxiety, mean (SD) & & $3.6(3.4)$ & $3.5(3.4)$ & $3.4(3.5)$ & $2.9(3.1)$ \\
\hline Range (min-max) & & $0-16$ & $0-15$ & $0-16$ & $0-16$ \\
\hline Inflammatory markers, median (IQR) & & & & & \\
\hline IL6 in pg/mL & $1.1(0.7-1.7)$ & $1.5(0.8-2.2)$ & $1.2(0.8-2.0)$ & $0.9(0.6-1.4)$ & $0.9(0.5-1.5)$ \\
\hline IL8 in pg/mL & $5.5(4.4-8.0)$ & $5.6(4.4-7.3)$ & $5.2(4.4-7.0)$ & $3.9(3.1-4.8)$ & $4.8(3.8-6.2)$ \\
\hline IL10 in pg/mL & $0.3(0.2-0.4)$ & $0.4(0.3-0.5)$ & $0.4(0.2-0.5)$ & $0.2(0.2-0.4)$ & $0.2(0.1-0.3)$ \\
\hline $\mathrm{TNF} \alpha$ in $\mathrm{pg} / \mathrm{mL}$ & $2.2(1.8-2.8)$ & $2.9(2.4-3.8)$ & $2.8(2.3-3.6)$ & $2.0(1.6-2.5)$ & $2.0(1.6-2.9)$ \\
\hline Summary z-score & $-0.1(-1.4$ to 1.1$)$ & $-0.1(-1.5$ to 1.1$)$ & $-0.2(-1.1$ to 1.1$)$ & $-0.3(-1.4$ to 1.0$)$ & 0.1 ( -1.5 to 1.3$)$ \\
\hline Sun exposure ${ }^{f}, n(\%)$ & & & & & \\
\hline$<7$ days & $87(33)$ & $119(46)$ & $87(41)$ & 65 (39) & $32(44)$ \\
\hline 7 days & $173(67)$ & $141(54)$ & $124(59)$ & $102(61)$ & $40(56)$ \\
\hline Number of comorbidities, $n$ (\%) & & & & & \\
\hline None & $49(19)$ & $55(21)$ & $49(21)$ & $41(24)$ & $16(21)$ \\
\hline 1 & $57(22)$ & $64(25)$ & $51(24)$ & $39(23)$ & $17(22)$ \\
\hline$\geq 2$ & $155(59)$ & $141(54)$ & $113(53)$ & $87(52)$ & $43(57)$ \\
\hline $\mathrm{BMI}$ in $\mathrm{kg} / \mathrm{m}^{2}$, mean (SD) & $28.4(4.5)$ & $27.7(4.4)$ & $28.2(4.4)$ & $28.5(4.5)$ & $28.5(5.0)$ \\
\hline Physical activity, median (IQR) & & & & & \\
\hline LPA (hours/week) & $11(4-23)$ & $8(2-16)$ & $11(4-21)$ & $11(3-22)$ & $11(5-24)$ \\
\hline MVPA (hours/week) & $11(5-20)$ & $7(3-14)$ & $9(4-15)$ & $9(4-18)$ & $8(3-18)$ \\
\hline Current smoking, $n(\%)$ & & & & & \\
\hline Yes & $33(13)$ & $24(9)$ & $17(8)$ & $17(10)$ & $6(8)$ \\
\hline No & $227(87)$ & $235(91)$ & $194(92)$ & $150(90)$ & $66(92)$ \\
\hline
\end{tabular}

Abbreviations: BMI, body mass index; LPA, light physical activity; MVPA, moderate-to-vigorous physical activity.

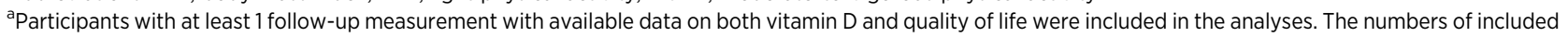
participants decrease during follow-up because data collected until November 1, 2016, were used and participants had not yet reached their follow-up measurement at that time. The number of participants may slightly vary for the different variables given a small percentage of missing data.

bietary intake of vitamin D was measured by a semiquantitative 253 -item food frequency questionnaire at diagnosis, and by a 7-day dietary record at each follow-up measurement.

${ }^{\mathrm{C}}$ Ranges EORTC QLQ-C30 subscales: 0-100.

${ }^{\mathrm{d}}$ Ranges CIS: total score, 20-140; subjective fatigue, 8-56; reduced motivation, 4-28; reduced physical activity, 3-21; concentration problems, 5-35.

${ }^{\text {e}}$ Ranges HADS: total score, 0-42; depression, 0-21; anxiety, 0-21.

${ }^{\mathrm{f}}$ Number of days per week spent at least 15 minutes outside (in daylight), on average over the preceding 4 weeks. 
Vitamin D and Quality of Life after Colorectal Cancer

modeled separately as the independent variable in multivariable adjusted models to obtain more insight into the role of vitamin D supplement use.

A summary score for the inflammatory markers was calculated by summing z-scores of natural-log transformed concentrations of IL6, IL8, and TNF $\alpha$, and subtracting IL10, for each time point (47). Higher scores are indicative of higher inflammation.

Relevant confounders were preselected according to the literature and included sex, age at diagnosis, time since diagnosis (units of 6 months), cancer treatment (neither chemotherapy nor radiotherapy, chemotherapy only, radiotherapy only, or both), number of comorbidities $(0,1$, or $\geq 2)$, MVPA (h/wk), and BMI $\left(\mathrm{kg} / \mathrm{m}^{2}\right)$. All time-dependent variables, including confounders, were included in the model as the repeated measurements. Other potential covariates that did not change the beta-coefficients for the relationship of main exposures with outcomes, and therefore not included in the models, were: inflammatory markers (z-score), $25 \mathrm{OHD}_{3}$ at diagnosis, season, vitamin D intake from supplements $(\mu \mathrm{g} / \mathrm{d})$, and sun exposure (dichotomous: spent 15 minutes outside on 7 or $<7$ days/week). Subgroup analyses were performed for sex (men/women), age at diagnosis ( $<70$ and $\geq 70$ years), vitamin $D$ supplement use (users/nonusers), and (neo-)adjuvant chemotherapy (yes/no).

Statistical analyses were performed using Stata15 (StataCorp.). $P$ values $<0.05$ (two-sided) were considered as statistically significant.

\section{Results}

\section{Participant characteristics}

The 261 participants who enrolled in the study ( $31 \%$ women) had a mean \pm SD age of $67 \pm 9$ years (Table 1). Median $25 \mathrm{OHD}_{3}$ concentrations decreased after diagnosis and subsequently increased during follow-up (Table 2, Fig. 1). Almost half (45\%) of participants were vitamin $\mathrm{D}$ deficient $(<50 \mathrm{nmol} / \mathrm{L})$ at diagnosis. Regarding the subgroups advised to use extra vitamin D, $24 \%$ of men and women aged $\geq 70$ years $(n=98)$ were vitamin D supplement users at diagnosis. In addition, $33 \%$ of women aged $50-70$ years $(n=39)$ used vitamin D supplements at diagnosis. Users of vitamin D supplements had higher serum concentrations compared with nonusers (Fig. 1B). Participants who received chemotherapy had consistently lower concentrations compared with the group who did not receive chemotherapy (Fig. 1C).

\section{Vitamin D and HRQoL}

With every 6 months, global quality of life scores improved on average by 1.3 points [ $95 \%$ confidence interval $(\mathrm{CI}), 0.4-2.1$ ], and fatigue levels decreased by 2.8 points ( $95 \% \mathrm{CI},-3.8$ to -1.8 ; EORTC) and 3.3 points ( $95 \%$ CI, -4.3 to -2.2 ; CIS; Table 3, Supplementary Fig. S1).

$25 \mathrm{OHD}_{3}$ was longitudinally associated with better global quality of life $(\beta 2.9 ; 95 \% \mathrm{CI}, 1.5-4.3)$ and reduced fatigue (EORTC: $\beta-3.5 ; 95 \%$ CI, -5.3 to -1.8 and CIS: $\beta-2.8 ; 95 \%$ CI, -4.7 to -0.9 ). An increase of $20 \mathrm{nmol} / \mathrm{L} 25 \mathrm{OHD}_{3}$ within an individual over time was associated with an average 3.7 point $(95 \% \mathrm{CI}, 1.7-5.6)$ higher global quality of life score. In addition, a $20 \mathrm{nmol} / \mathrm{L}$ higher mean $25 \mathrm{OHD}_{3}$ concentration between individuals over time was associated with an average 2.1 point $(95 \% \mathrm{CI}, 0.2-4.1)$ higher global quality of life score. Intra- and interindividual associations of $25 \mathrm{OHD}_{3}$ with fatigue were of similar degree when measured by the CIS ( $\beta$ 's -2.5 and -3.2 , respectively), whereas for fatigue as measured by the EORTC, the association for intraindividual changes was stronger compared with interindividual
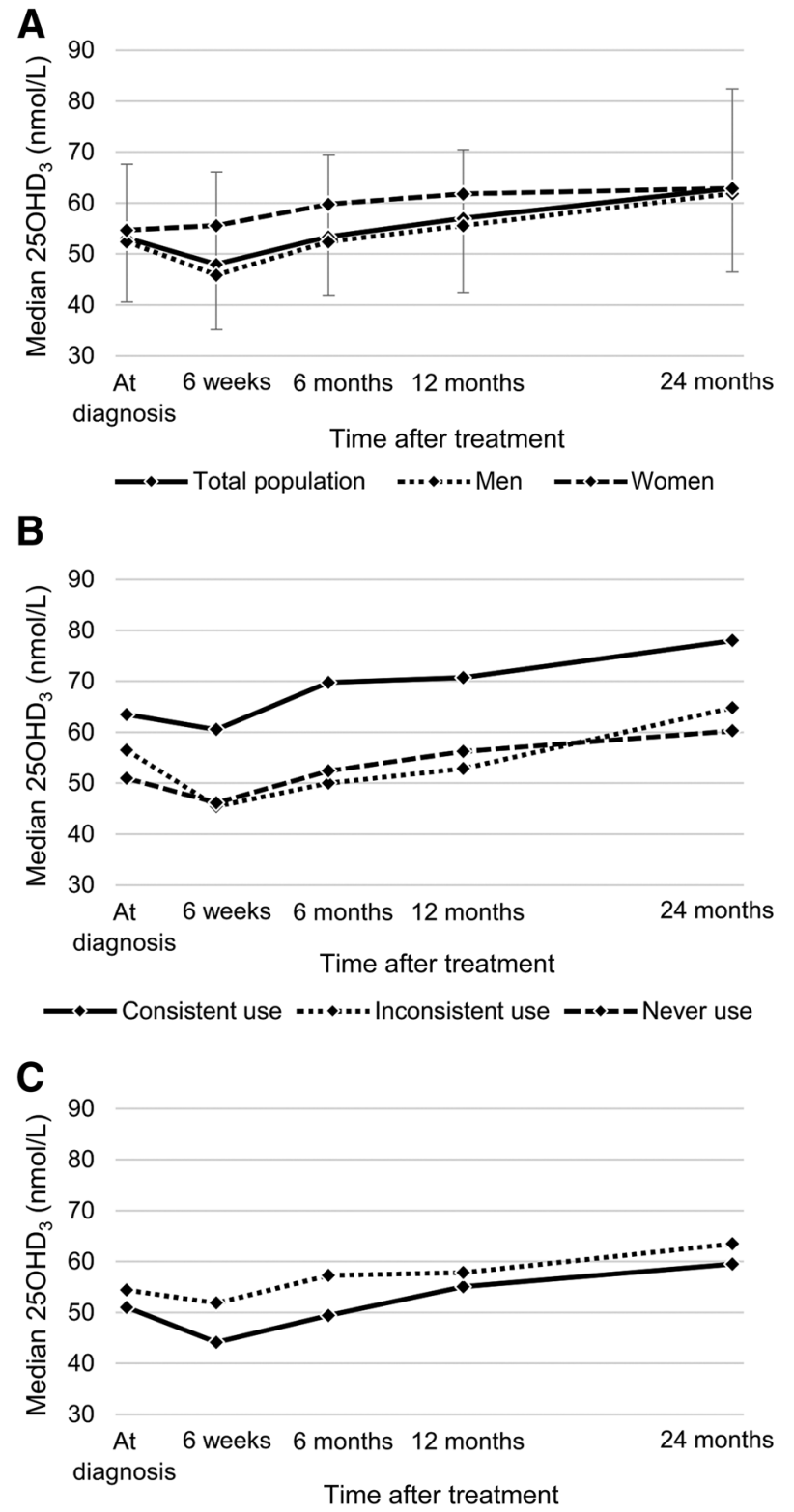

-*Chemotherapy $\quad$-....... No chemotherapy

Figure 1.

Median concentrations of $250 \mathrm{HD}_{3}$ over time from colorectal cancer diagnosis (study inclusion) to 24 months after treatment for patients with colorectal cancer included in the EnCoRe study, in the total population (with IQR) and stratified by sex (A), stratified by vitamin D supplement user type (B), and stratified by chemotherapy (C). The actual time between the measurement at diagnosis and the measurement 6 weeks after treatment can vary between individual patients due to differences in treatment duration.

differences ( $\beta$ 's -4.4 and -2.6 , respectively). Not being vitamin $D$ deficient was longitudinally associated with better global quality of life ( $\beta$ 4.4; 95\% CI, $1.6-7.2)$ and less fatigue (EORTC: $\beta-5.2 ; 95 \% \mathrm{CI}$, -8.6 to -1.8 and CIS: $\beta-5.4 ; 95 \%$ CI, -9.0 to -1.8 ), both within and between individuals (Table 3). Dose-response relations were observed for the outcomes global quality of life and fatigue when comparing the scoring of participants having severely deficient $(<30 \mathrm{nmol} / \mathrm{L})$ and 
Koole et al.

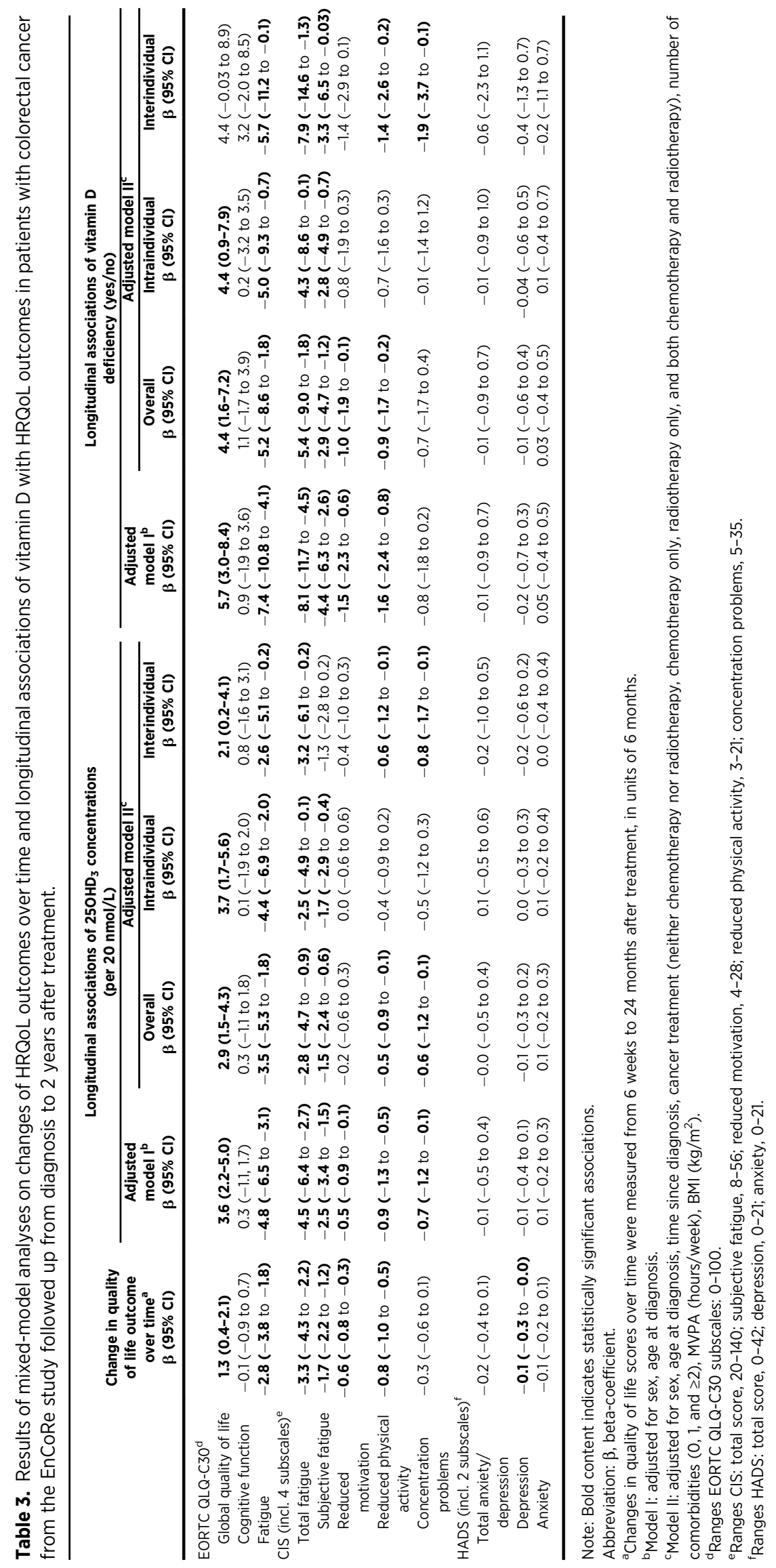




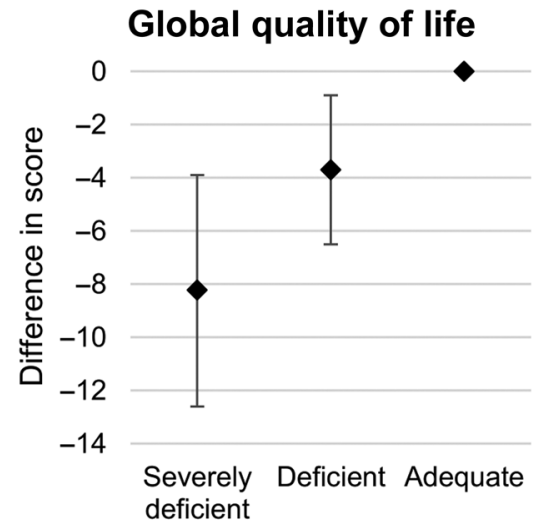

Fatigue (CIS)

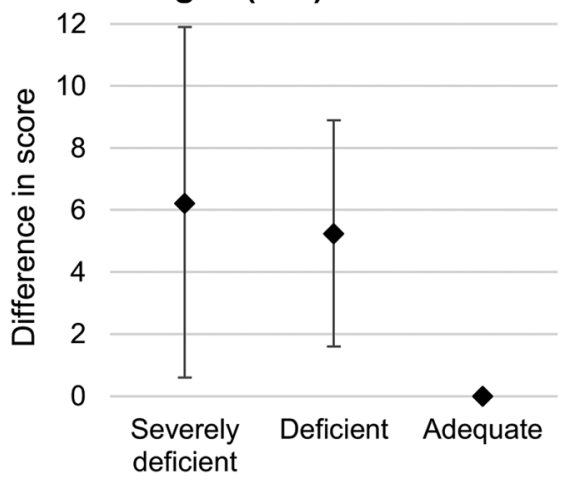

Cognitive functioning

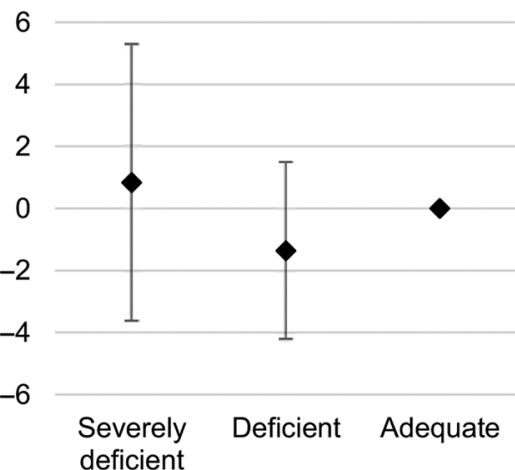

Fatigue (EORTC QLQ-C30)

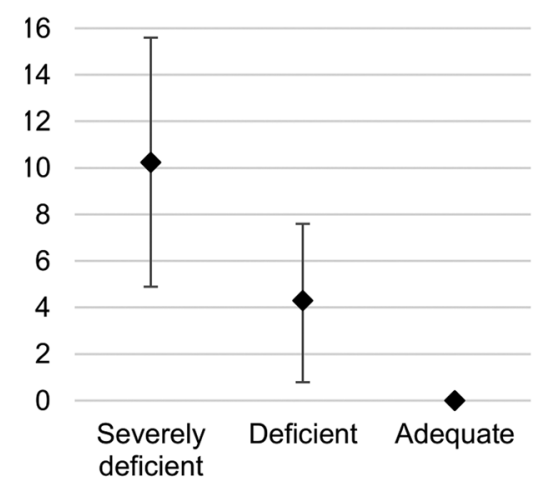

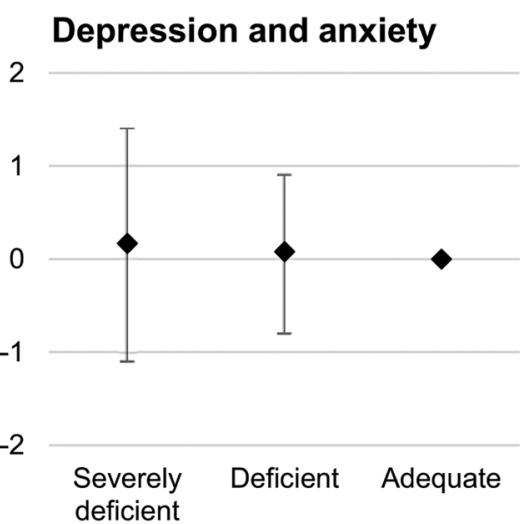

Figure 2.

Comparison of scoring on quality of life outcomes over time for participants having severely deficient $(<30 \mathrm{nmol} / \mathrm{L})$ and deficient $(30-50 \mathrm{nmol} / \mathrm{L}) 25 \mathrm{OHD} 3$ concentrations, with participants having adequate concentrations ( $>50 \mathrm{nmol} / \mathrm{L})$, from 6 weeks to 24 months after treatment in patients with colorectal cancer from the EnCoRe study.

deficient $(30-50 \mathrm{nmol} / \mathrm{L}) 25 \mathrm{OHD}_{3}$ concentrations, with participants having adequate concentrations ( $>50 \mathrm{nmol} / \mathrm{L}$; Fig. 2).

Although not statistically significant, better global quality of life and less fatigue (EORTC QLQ-C30) were observed for individuals who changed from being nonuser to user of vitamin D supplements over time, whereas interindividual differences suggested lower global quality of life and more fatigue for supplement users compared with nonusers (Table 4). No longitudinal associations were found between the sum of dietary and supplemental vitamin D intake with global quality of life and fatigue, and between vitamin $\mathrm{D}$ intake from supplements only and these outcomes.

In subgroup analyses, longitudinal associations of $25 \mathrm{OHD}_{3}$ concentrations with global quality of life and fatigue were only present in men (Supplementary Table S1).

\section{Discussion}

To our knowledge, the current study is the first to investigate longitudinal associations between serum $25 \mathrm{OHD}_{3}$ concentrations and HRQoL outcomes in colorectal cancer survivors. Higher concentrations of $25 \mathrm{OHD}_{3}$ were longitudinally associated with better global quality of life and less fatigue from 6 weeks up to 2 years after colorectal cancer treatment, both within and between individuals. In addition, having a vitamin $\mathrm{D}$ deficiency was associated with lower global quality of life and more fatigue. Intraindividual associations suggested better global quality of life and less fatigue for individuals who started using vitamin D supplements during follow-up.

The prevalence of vitamin D deficiency increased from $45 \%$ at diagnosis to $53 \% 6$ weeks after treatment (cutoff $50 \mathrm{nmol} / \mathrm{L}$ ). The latter is slightly higher compared with the general Dutch population aged $60+$ with prevalences of $34 \%$ to $51 \%$ (48). A study among 2,910 patients with stage I-IV colorectal cancer from Germany observed deficiencies in $84 \%$ of participants, yet samples were assessed approximately 3 weeks after diagnosis (49). Another study among 1,598 Scottish patients with stage I-III colorectal cancer found concentrations $<25 \mathrm{nmol} / \mathrm{L}$ among $50 \%$ of participants approximately 15 weeks after treatment (50). This compares with only $10 \%$ of participants when using the cutoff point of $25 \mathrm{nmol} / \mathrm{L}$ in our population. Differences may be due to vitamin D supplement use, latitude, and time of sampling as concentrations in our study steadily increased after treatment. Nevertheless, the important health concern of vitamin D deficiency among this group of patients is indisputable.

Previous studies examining the potential relation between vitamin $\mathrm{D}$ and aspects of HRQoL are still inconclusive and scarce among population subgroups such as cancer survivors. A systematic literature review concluded a moderate positive effect of short-term vitamin D supplementation on HRQoL in clinical populations, not including cancer survivors (51). Despite the large heterogeneity between studies included in this review, results correspond to the observed associations 
of the current study. Regarding fatigue, contradicting results were found in two intervention studies. A randomized placebo-controlled trial among patients with chronic fatigue syndrome found no effect of vitamin D supplementation (52), whereas another trial for treating fatigue among otherwise healthy individuals observed lower fatigue among vitamin D supplement users compared with a placebo group (53). A retrospective study among 100 ambulatory advanced cancer patients, including patients with gastrointestinal cancer, found no association between vitamin $\mathrm{D}$ concentrations and symptoms of depression, anxiety, and fatigue (54). Our study neither found associations between serum $25 \mathrm{OHD}_{3}$ concentrations and depression, anxiety, and cognitive functioning, potentially caused by the lack of variation over time in these outcomes. In summary, results from the current study are largely in line with the literature, yet comparing results is difficult given the large differences in methodology and study parameters between studies.

The observed effect sizes for associations with global quality of life and fatigue were small and could raise questions about clinical relevance. Minimally important differences for global quality of life and fatigue (EORTC QLQ-C30) were defined as 10 and 9 points $(55,56)$, respectively, and for overall fatigue (CIS) as 10 points (57). Increments of $20 \mathrm{nmol} / \mathrm{L} 25 \mathrm{OHD}_{3}$ were used as clinically relevant contrast as it resembled $1 \mathrm{SD}$ and represented realistic fluctuations in intraindividual $25 \mathrm{OHD}_{3}$ concentrations. Although effect sizes were larger in dichotomous analyses (vitamin D deficiency yes/no), none of the effect sizes reached the level of clinical relevance. Nevertheless, observed beta-coefficients suggest the presence of a longitudinal association between higher $25 \mathrm{OHD}_{3}$ and better HRQoL.

An important strength of the current study was the prospective character with repeated measurements of $25 \mathrm{OHD}_{3}$ and HRQoL outcomes. Further, follow-up response rates were high, and the percentage of missing data was low. Another strength was the use of mixed-model analysis techniques that enabled disentangling of inter- and intraindividual associations, thereby providing additional insights into the nature of the associations. A limitation of the current study concerns the inability to draw conclusions on causality. Observed associations could be due to the fact that colorectal cancer survivors with poorer HRQoL spend more time indoors, resulting in lower $25 \mathrm{OHD}_{3}$ concentrations. However, adjustment for sun exposure did not change the associations. In addition, despite adjustment for important variables such as therapy, residual confounding may have occurred, as observed associations could be caused by unmeasured underlying factors related to the cancer that also influenced biological mechanisms related to $25 \mathrm{OHD}_{3}$ and HRQoL.

The use of vitamin D supplements was low despite the national recommendations that applied to about half of the study population. Although vitamin D supplement users on average had higher serum $25 \mathrm{OHD}_{3}$ concentrations compared with nonusers, no direct beneficial association of vitamin D supplement use with HRQoL was found. In addition, associations of $25 \mathrm{OHD}_{3}$ with global quality of life and fatigue were also present in participants not using vitamin $\mathrm{D}$ supplements. In fact, vitamin $\mathrm{D}$ supplement use itself seemed associated with poorer HRQoL and more fatigue in interindividual associations. An alternative explanation, also hypothesized by Patterson and colleagues (58), is that supplement use may be a coping strategy rather than actually improving health of cancer survivors. Associations with supplement use should therefore be interpreted with caution, because individuals with poorer HRQoL and more fatigue may begin to use (vitamin D) supplements as a way to alleviate complaints (5). Intraindividual associations 
contrarily suggested that individuals who started using supplements during follow-up were generally likely to report better global quality of life and less fatigue. Whether this association is causal needs to be addressed in intervention studies.

Our study does not provide strong enough evidence to formulate recommendations on the necessity of vitamin $\mathrm{D}$ supplementation for colorectal cancer survivors. However, higher $25 \mathrm{OHD}_{3}$ concentrations seem beneficial, and colorectal cancer survivors are advised to follow the guidelines for the general Dutch population because no specific guidelines on vitamin $\mathrm{D}$ for cancer survivors are available. According to the national guidelines, women aged $>50$ and women and men aged $>70$ are recommended to use vitamin D supplements (10 and $20 \mathrm{mcg}$, respectively) to ensure adequate blood concentrations for the prevention of osteoporosis (14). In addition, all colorectal cancer survivors should spend the recommended time outdoors to sufficiently expose their skin to sunlight (17). In practice, however, many colorectal cancer survivors seem unaware of the prevailing recommendations, potentially as a consequence of the lack of proper information provided.

In conclusion, our results suggest that higher $25 \mathrm{OHD}_{3}$ concentrations are longitudinally associated with better global quality of life and reduced fatigue in colorectal cancer survivors. It is important for colorectal cancer survivors to become aware of the national guidelines regarding sun exposure and vitamin $\mathrm{D}$ supplementation, and individual $25 \mathrm{OHD}_{3}$ status should be monitored by medical professionals. Placebo-controlled randomized trials are needed to examine the potential advantage of the use of vitamin D supplements in colorectal cancer survivors for improvement of HRQoL and fatigue to clarify questions on cause and effect and to deepen the understanding of possible underlying mechanisms.

\section{Disclosure of Potential Conflicts of Interest}

No potential conflicts of interest were disclosed.

\section{References}

1. Denlinger CS, Barsevick AM. The challenges of colorectal cancer survivorship. J Natl Compr Canc Netw 2009;7:883-93

2. Integraal Kankercentrum Nederland. Nederlandse Kankerregistratie; 2019. Available from: https://www.cijfersoverkanker.nl/selecties/Overleving_darm/ img5c598055e0605.

3. Thong MS, Mols F, Wang XS, Lemmens VE, Smilde TJ, van de Poll-Franse LV. Quantifying fatigue in (long-term) colorectal cancer survivors: a study from the population-based patient reported outcomes following initial treatment and long term evaluation of survivorship registry. Eur J Cancer 2013;49:1957-66.

4. Husson O, Mols F, van de Poll-Franse L, de Vries J, Schep G, Thong MS Variation in fatigue among 6011 (long-term) cancer survivors and a normative population: a study from the population-based PROFILES registry. Support Care Cancer 2015;23:2165-74.

5. Koole JL, Bours MJL, Breedveld-Peters JJL, van Roekel EH, Breukink SO, Janssen-Heijnen MLG, et al. Is dietary supplement use longitudinally associated with fatigue in stage I-III colorectal cancer survivors? Clin Nutr 2020;39:234-41.

6. Vardy J, Dhillon HM, Pond GR, Rourke SB, Xu W, Dodd A, et al. Cognitive function and fatigue after diagnosis of colorectal cancer. Ann Oncol 2014;25: 2404-12.

7. Cruzado JA, Lopez-Santiago S, Martinez-Marin V, Jose-Moreno G, Custodio $\mathrm{AB}$, Feliu J. Longitudinal study of cognitive dysfunctions induced by adjuvant chemotherapy in colon cancer patients. Support Care Cancer 2014;22:1815-23.

8. Lloyd S, Baraghoshi D, Tao R, Garrido-Laguna I, Gilcrease GW 3rd, Whisenant J, et al. Mental health disorders are more common in colorectal cancer survivors and associated with decreased overall survival. Am J Clin Oncol 2019;42:355-62.

9. Krause D, Roupas P. Effect of vitamin intake on cognitive decline in older adults: evaluation of the evidence. J Nutr Health Aging 2015;19:745-53.

\section{Authors' Contributions}

Conception and design: J.L. Koole, M.J.L. Bours, M.P. Weijenberg

Development of methodology: J.L. Koole, M.J.L. Bours, E.H. van Roekel, J.J.L. Breedveld-Peters, M.P. Weijenberg

Acquisition of data (provided animals, acquired and managed patients, provided facilities, etc.): J.L. Koole, E.H. van Roekel, J.J.L. Breedveld-Peters, F.J.B. van Duijnhoven, E.T.P. Keulen

Analysis and interpretation of data (e.g., statistical analysis, biostatistics, computational analysis): J.L. Koole, F.J.B. van Duijnhoven, J. van den Ouweland, M.P. Weijenberg

Writing, review, and/or revision of the manuscript: J.L. Koole, M.J.L. Bours, E.H. van Roekel, J.J.L. Breedveld-Peters, F.J.B. van Duijnhoven, J. van den Ouweland, S.O. Breukink, M.L.G. Janssen-Heijnen, E.T.P. Keulen, M.P. Weijenberg Administrative, technical, or material support (i.e., reporting or organizing data, constructing databases): J.L. Koole

Study supervision: M.J.L. Bours, M.P. Weijenberg

\section{Acknowledgments}

The EnCoRe study was supported by grants from the Stichting Alpe d'HuZes within the research program "Leven met kanker" of the Dutch Cancer Society (Gran Nos. UM-2010-4867 and UM-2012-5653), by grants from Kankeronderzoekfonds Limburg as part of Health Foundation Limburg (Grant No. 00005739), and by a grant from Wereld Kanker Onderzoek Fonds (WKOF), as part of the World Cancer Research Fund International grant program (grant number 2016/1620).

We would like to thank all participants of the EnCoRe study and the health professionals in the three hospitals involved in the recruitment of participants of the study: Maastricht University Medical Centre+, VieCuri Medical Centre, and Zuyderland Medical Centre. We would also like to thank the MEMIC center for data and information management for facilitating the logistic processes and data management of our study. We thank Michiel Balvers and Nhien Ly for their work on the inflammation markers. Finally, we would like to thank the research dietitians and research assistants who are responsible for patient inclusion and follow-up, performing home visits, as well as data collection and processing.

The costs of publication of this article were defrayed in part by the payment of page charges. This article must therefore be hereby marked advertisement in accordance with 18 U.S.C. Section 1734 solely to indicate this fact.

Received December 9, 2019; revised February 4, 2020; accepted March 31, 2020 published first April 3, 2020

10. Goodwill AM, Szoeke C. A systematic review and meta-analysis of the effect of low vitamin D on cognition. J Am Geriatr Soc 2017;65:2161-8.

11. Anglin RE, Samaan Z, Walter SD, McDonald SD. Vitamin D deficiency and depression in adults: systematic review and meta-analysis. Br J Psychiatry 2013 202:100-7.

12. Parker GB, Brotchie H, Graham RK. Vitamin D and depression. J Affect Disord 2017;208:56-61

13. Hock AD. Review: vitamin D3 deficiency results in dysfunctions of immunity with severe fatigue and depression in a variety of diseases. In Vivo 2014;28 133-45.

14. Health Council of the Netherlands. Evaluation of the dietary reference values for vitamin D. The Hague (the Netherlands): Health Council of the Netherlands 2012.

15. Hossein-nezhad A, Holick MF. Optimize dietary intake of vitamin D: an epigenetic perspective. Curr Opin Clin Nutr Metab Care 2012;15:567-79.

16. Cashman KD, Dowling KG, Skrabakova Z, Gonzalez-Gross M, Valtuena J, De Henauw S, et al. Vitamin D deficiency in Europe: pandemic? Am J Clin Nutr 2016;103:1033-44

17. Dutch Cancer Society. The relation between cancer, sun exposure and vitamin D. Amsterdam (the Netherlands): Dutch Cancer Society; 2010.

18. Savoie MB, Paciorek A, Zhang L, Van Blarigan EL, Sommovilla N, Abrams D, et al. Vitamin D levels in patients with colorectal cancer before and after treatment initiation. J Gastrointest Cancer 2019;50:769-79.

19. Fakih MG, Trump DL, Johnson CS, Tian L, Muindi J, Sunga AY. Chemotherapy is linked to severe vitamin D deficiency in patients with colorectal cancer. Int Colorectal Dis 2009;24:219-24.

20. Holick MF. Vitamin D deficiency. N Engl J Med 2007;357:266-81. 
21. Ma Y, Zhang P, Wang F, Yang J, Liu Z, Qin H. Association between vitamin D and risk of colorectal cancer: a systematic review of prospective studies. J Clin Oncol 2011;29:3775-82.

22. Giovannucci E. Epidemiology of vitamin D and colorectal cancer. Anticancer Agents Med Chem 2013;13:11-9.

23. McCullough ML, Zoltick ES, Weinstein SJ, Fedirko V, Wang M, Cook NR, et al Circulating vitamin $\mathrm{D}$ and colorectal cancer risk: an international pooling project of 17 cohorts. J Natl Cancer Inst 2019;111:158-69.

24. Lee JE, Li H, Chan AT, Hollis BW, Lee IM, Stampfer MJ, et al. Circulating levels of vitamin D and colon and rectal cancer: the Physicians' Health Study and a metaanalysis of prospective studies. Cancer Prev Res 2011;4:735-43.

25. van Harten-Gerritsen AS, Balvers MG, Witkamp RF, Kampman E, van Duijnhoven FJ. Vitamin D, inflammation, and colorectal cancer progression: a review of mechanistic studies and future directions for epidemiological studies. Cancer Epidemiol Biomarkers Prev 2015;24:1820-8.

26. Bower JE. Cancer-related fatigue-mechanisms, risk factors, and treatments. Nat Rev Clin Oncol 2014;11:597-609.

27. Lewis C, Xun P, He K. Vitamin D supplementation and quality of life following diagnosis in stage II colorectal cancer patients: a 24-month prospective study. Support Care Cancer 2016;24:1655-61.

28. Demark-Wahnefried W, Peterson B, McBride C, Lipkus I, Clipp E. Current health behaviors and readiness to pursue life-style changes among men and women diagnosed with early stage prostate and breast carcinomas. Cancer 2000; $88: 674-84$

29. van Roekel EH, Bours MJ, de Brouwer CP, Ten Napel H, Sanduleanu S, Beets GL, et al. The applicability of the international classification of functioning, disability, and health to study lifestyle and quality of life of colorectal cancer survivors. Cancer Epidemiol Biomarkers Prev 2014;23:1394-405.

30. van den Ouweland JM, Beijers AM, van Daal H. Overestimation of 25-hydroxyvitamin D3 by increased ionisation efficiency of 3-epi-25hydroxyvitamin D3 in LC-MS/MS methods not separating both metabolites as determined by an LC-MS/MS method for separate quantification of 25-hydroxyvitamin D3, 3-epi-25-hydroxyvitamin D3 and 25-hydroxyvitamin D2 in human serum. J Chromatogr B Analyt Technol Biomed Life Sci 2014;967:195-202.

31. Seamans KM, Cashman KD. Existing and potentially novel functional markers of vitamin D status: a systematic review. Am J Clin Nutr 2009; 89:1997S-2008S.

32. Aaronson NK, Ahmedzai S, Bergman B, Bullinger M, Cull A, Duez NJ, et al. The European Organization for Research and Treatment of Cancer QLQ-C30: a quality-of-life instrument for use in international clinical trials in oncology. J Natl Cancer Inst 1993;85:365-76.

33. Fayers PM, Aaronson NK, Bjordal K, Groenvold M, Curran D, Bottomley A; on behalf of the EORTC Quality of Life Group. The EORTC QLQ-C30 scoring manual. 3rd ed. Brussels (Belgium): European Organisation for Research and Treatment of Cancer; 2001.

34. Vercoulen JH, Swanink CM, Fennis JF, Galama JM, van der Meer JW, Bleijenberg G. Dimensional assessment of chronic fatigue syndrome. J Psychosom Res 1994; 38:383-92.

35. Servaes $P$, Verhagen C, Bleijenberg G. Fatigue in cancer patients during and after treatment: prevalence, correlates and interventions. Eur J Cancer 2002;38:27-43.

36. Zigmond AS, Snaith RP. The hospital anxiety and depression scale. Acta Psychiatr Scand 1983;67:361-70.

37. Bjelland I, Dahl AA, Haug TT, Neckelmann D. The validity of the Hospital Anxiety and Depression Scale. An updated literature review. J Psychosom Res 2002;52:69-77.

38. Charlson ME, Pompei P, Ales KL, MacKenzie CR. A new method of classifying prognostic comorbidity in longitudinal studies: development and validation. J Chronic Dis 1987;40:373-83.

39. Sangha O, Stucki G, Liang MH, Fossel AH, Katz JN. The Self-Administered Comorbidity Questionnaire: a new method to assess comorbidity for clinical and health services research. Arthritis Rheum 2003;49:156-63.
40. Koole JL, Bours MJL, Breedveld-Peters JJL, van Roekel EH, van Dongen M, Eussen S, et al. Evaluating the validity of a food frequency questionnaire in comparison with a 7-day dietary record for measuring dietary intake in a population of survivors of colorectal cancer. J Acad Nutr Diet 2020;120:245-57.

41. RIVM/Voedingscentrum. Dutch Food Composition (NEVO) Table 2011. The Hague (the Netherlands): Netherlands Nutrition Center; 2011.

42. Breedveld-Peters JJL, Koole JL, Muller-Schulte E, van der Linden BWA, Windhausen C, Bours MJL, et al. Colorectal cancers survivors' adherence to lifestyle recommendations and cross-sectional associations with health-related quality of life. Br J Nutr 2018;120:188-97.

43. Wendel-Vos GC, Schuit AJ, Saris WH, Kromhout D. Reproducibility and relative validity of the short questionnaire to assess health-enhancing physical activity. J Clin Epidemiol 2003;56:1163-9.

44. Zhang H, Ahn J, Yu K. Comparing statistical methods for removing seasonal variation from vitamin D measurements in case-control studies. Stat Interface 2011;4:85-93.

45. Cleveland WS, Devlin SJ. Locally weighted regression: an approach to regression analysis by local fitting. J Am Statist Assoc 1988;83:596-610.

46. Twisk JWR, de Vente W. Hybrid models were found to be very elegant to disentangle longitudinal within- and between-subject relationships. J Clin Epidemiol 2019;107:66-70.

47. Hopkins MH, Owen J, Ahearn T, Fedirko V, Flanders WD, Jones DP, et al. Effects of supplemental vitamin $\mathrm{D}$ and calcium on biomarkers of inflammation in colorectal adenoma patients: a randomized, controlled clinical trial. Cancer Prev Res 2011;4:1645-54.

48. Health Council of the Netherlands. Towards an adequate intake of vitamin D. The Hague (the Netherlands): Health Council of the Netherlands, 2008.

49. Maalmi H, Walter V, Jansen L, Chang-Claude J, Owen RW, Ulrich A, et al. Relationship of very low serum 25-hydroxyvitamin D3 levels with long-term survival in a large cohort of colorectal cancer patients from Germany. Eur J Epidemiol 2017;32:961-71.

50. Zgaga L, Theodoratou E, Farrington SM, Din FV, Ooi LY, Glodzik D, et al. Plasma vitamin $\mathrm{D}$ concentration influences survival outcome after a diagnosis of colorectal cancer. J Clin Oncol 2014;32:2430-9.

51. Hoffmann MR, Senior PA, Mager DR. Vitamin D supplementation and healthrelated quality of life: a systematic review of the literature. J Acad Nutr Diet 2015; 115:406-18.

52. Witham MD, Adams F, McSwiggan S, Kennedy G, Kabir G, Belch JJ, et al. Effect of intermittent vitamin D3 on vascular function and symptoms in chronic fatigue syndrome-a randomised controlled trial. Nutr Metab Cardiovasc Dis 2015;25: 287-94.

53. Nowak A, Boesch L, Andres E, Battegay E, Hornemann T, Schmid C, et al. Effect of vitamin D3 on self-perceived fatigue: a double-blind randomized placebocontrolled trial. Medicine 2016;95:e5353.

54. Dev R, Del Fabbro E, Schwartz GG, Hui D, Palla SL, Gutierrez N, et al Preliminary report: vitamin $\mathrm{D}$ deficiency in advanced cancer patients with symptoms of fatigue or anorexia. Oncologist 2011;16:1637-41.

55. Cocks K, King MT, Velikova G, Martyn St-James M, Fayers PM, Brown JM. Evidence-based guidelines for determination of sample size and interpretation of the European Organisation for the Research and Treatment of Cancer Quality of Life Questionnaire Core 30. J Clin Oncol 2011;29:89-96.

56. Jayadevappa R, Cook R, Chhatre S. Minimal important difference to infer changes in health-related quality of life-a systematic review. J Clin Epidemiol 2017;89:188-98.

57. Peters JB, Heijdra YF, Daudey L, Boer LM, Molema J, Dekhuijzen PN, et al. Course of normal and abnormal fatigue in patients with chronic obstructive pulmonary disease, and its relationship with domains of health status. Patient Educ Couns 2011;85:281-5.

58. Patterson RE, Neuhouser ML, Hedderson MM, Schwartz SM, Standish LJ, Bowen DJ. Changes in diet, physical activity, and supplement use among adults diagnosed with cancer. J Am Diet Assoc 2003;103:323-8. 


\section{Cancer Epidemiology, Biomarkers \& Prevention}

\section{Higher Serum Vitamin D Concentrations Are Longitudinally Associated with Better Global Quality of Life and Less Fatigue in Colorectal Cancer Survivors up to 2 Years after Treatment}

Janna L. Koole, Martijn J.L. Bours, Eline H. van Roekel, et al.

Cancer Epidemiol Biomarkers Prev 2020;29:1135-1144. Published OnlineFirst April 3, 2020.

Updated version Access the most recent version of this article at: doi:10.1158/1055-9965.EPI-19-1522

Supplementary Access the most recent supplemental material at:

Material http://cebp.aacrjournals.org/content/suppl/2020/04/03/1055-9965.EPI-19-1522.DC1

Cited articles This article cites 52 articles, 13 of which you can access for free at: http://cebp.aacrjournals.org/content/29/6/1135.full\#ref-list-1

E-mail alerts Sign up to receive free email-alerts related to this article or journal.

Reprints and To order reprints of this article or to subscribe to the journal, contact the AACR Publications Department Subscriptions at pubs@aacr.org.

Permissions To request permission to re-use all or part of this article, use this link http://cebp.aacrjournals.org/content/29/6/1135.

Click on "Request Permissions" which will take you to the Copyright Clearance Center's (CCC) Rightslink site. 